\title{
Investigate Competitive Intelligence Process: An Exploratory Study in Tunisian Companies
}

\author{
Wadie Nasri \\ (Ph.D., Faculty of Economics Sciences and Management of Tunis) \\ Assistant Professor of Management in the Higher Institute of Management of Gabes \\ Street, Jilani EL HABIB 6000, Gabes, Gabes University, Tunisia \\ E-mail: wadienasri@yahoo.fr
}

Received: June 6, 2011

Accepted: June 16, 2011

doi:10.5539/ibr.v4n4p62

\begin{abstract}
The purpose of this study is to explore the aspects of management of competitive intelligence process in Tunisian companies. This exploratory study was conducted using semi-in-depth interviews with six executives in six companies in Tunisia. The results revealed by this study that the competitive intelligence as a competitive tool is unknown to the vast majority of Tunisian companies. It is not still a formalized stage, but it is in an embryonic way. Second, two most important of information are collected: profiles of potentials customers, and opportunities in new market. Thirdly, for analysing and synthesising information the results indicate that managers knows and uses the majority of methods to analyze competitive information gathered especially in making decisions that fall the marketing department. Fourthly, all companies spend most of their time in collecting information. Although planning what and how to collect information and analysis they receive relatively less attention. This research suggests that overriding influence on successful competitive intelligence process is the existence of a management support, culture and structure, which encourage and develop competitive intelligence activities in companies.
\end{abstract}

Keywords: Companies, Strategic management, Marketing intelligence, Information transfer, Tunisia

\section{Introduction}

Environmental changes, including shifting market structures, technical opportunities and increasingly rapid political shifts, are compelling executives and organizations to collect, analyse, decide and act on environmental information ever more quickly (Huber, 1984; Bower, 1986; Huber and Mcdaniel, 1986, Eisenhardt, 1989). In this context, recognition of changes' entity and market, competition, technology, innovation, customers' behavioral patterns, and the prediction of future trends are necessary for competition (Gabbar, 2007).

The analysis of information about the competitive environment is critical for a firm's capacity to successfully introduce new products, processes and services (Tidd et al., 2001; Salles, 2006). In recent years, competitive intelligence has become significant in management discipline and strategic management (Zangoueinezhad et al, 2008). The goal of this activity is to provide actionable intelligence that will provide a competitive edge to the organization (Kahaner, 1998).

Competitive intelligence is a process involving the gathering, analyzing, and communicating of environmental information to assist in strategic decision-making. It is the fundamental basis of the strategic decision-making process (Dichman P., 2007).

Competitive intelligence is an important source of information for business planning and other activities because it provides information about present and future behavior of competitors and the general business environment (Vedder and Guynes, 2002). Competitive intelligence systems are designed to help organizations make better strategic decisions (Troyd et al, 1993).

Successful use of Competitive intelligence allows a business to be knowledgeable and aware of what is happening in its environment (Barson, 2002). Consequently, many organizations are starting to recognize competitive intelligence as a critical component to making the best strategic and tactical decisions (Zangoueinezhad et al, 2008). In today's unpredictable economy, corporations turn to Competitive intelligence to build and maintain an edge. This paper intends to analyze the following aspects of management of Competitive intelligence process in Tunisian companies.

What is the organization set up for Competitive intelligence?

What is the process of Competitive intelligence?

What factors are analyzed for Competitive intelligence? 
What are the sources of information that companies tap?

What factors those promote competitive intelligence process in the Tunisian companies?

The remainder of the paper presents a brief literature overview of Competitive intelligence, followed by the methodology used in the research. The results are subsequently presented. This paper concludes with recommendations on how to improve the Competitive intelligence practices in Tunisian companies.

\section{Defining competitive intelligence}

Competitive intelligence can be defined as " actionable recommendations arising from a systematic process involving planning, gathering, analysing and disseminating information on the external environment for opportunities, or developments that have the potential to affect a company's or country's competitive situation" (Calof and Skinner (1999). It is also defined as "actionable information about the external business environment that could affect a company's competitive position (Ashton and Kalvans, 1997).

Competitive intelligence is information about the actions, capabilities, and intentions of current and potential competitors that provides input in formulating long-term strategy and goals (Troyd et al, 1993). Therefore, competitive intelligence includes competitor intelligence as well as intelligence collected on customers, suppliers, technologies, environments, or potential business relationships (Fair, 1966; Gilad, 1989; Grabowski, 1987; Guyton, 1962). It is the fundamental basis of the strategic decision-making process (Dichman P., 2007).

The intent of competitive intelligence is to better understand customers, regulators, competitors and so forth to create new opportunities and forecast changes in the quest for sustainable competitive advantage (Calof, 2006).

The most common benefit of Competitive intelligence however is its ability to build information profiles that helps a company to identify its competitor's strengths, weaknesses, strategies, objectives, market positioning and likely reaction patterns (Bose R., 2008). According to Berner S (2001), the functions of competitive intelligence are:

to prevent surprises that could hurt the business;

to identify opportunities for the organization;

to gain competitive advantage by reducing reaction time;

to improve long and short term planning;

to provide Actionable Intelligence for use in the development of strategies;

to engender a greater understanding of your own company;

to identify threats.

In recent years, Competitive intelligence has become significant in management discipline and strategic management (Zangoueinezhad et al, 2008). According to Kahana (1996), many reasons why companies need Competitive intelligence now more than ever:

The rapid increase in the pace of business: Businesses are required to handle more projects and make more decisions at greater speed than before.

Information overload: Technological development has accelerated the speed and availability of communication and information.

Increased global competition from new customers: Increased access to resources (e.g. capital, skills and transportation) increased the number of competitors and decreased the importance of close physical proximity.

Increasing aggressiveness of existing competition: Many market places are maturing resulting in companies increasing their market share at the expense of their competitors.

Quick and forceful effect of political changes: Many countries have moved from communism or socialism to capitalism in the last decades.

Rapid technological change: The last decades have seen the introduction of wireless communication, personal computers, the Internet and biotechnology.

When people talk about Competitive intelligence there tends to be confusion between Competitive intelligence and spying/espionage. Espionage is the practice of obtaining information about an organization or a society that is considered secret or confidential (spying) without the permission of the holder of the information (http://quinazagga.wordpress.com).

According to The Society of Competitive Intelligence Professionals (SCIP, 2008) Competitive intelligence is "a systematic and ethical process for gathering, analysing and managing external information that can affect the 
company's plans, decisions and operations". CI differs from spying in that is uses legal means and goes well beyond data collection.

Competitive intelligence is the art of collecting, processing and sorting information to be made available to people at all levels of the firm to help shape its future and protect it against current competitive threats (Zangoueinezhad et al, 2008). It should be legal and respect codes of ethics: it involves a transfer of knowledge from the environment to the organization within established rules.

\section{Competitive intelligence process}

The process of Competitive intelligence is the action of gathering, analyzing, and applying information about products, competitors, suppliers, regulators, partners, and customers for the short- and long-term planning needs of an organization (Kahaner, 1998). It is cited in literature as a four-phase process, consisting of formal and informal activities: planning and direction, data and information collection, analysis and dissemination of intelligence to those who will use it.

\subsection{Planning and Focus}

The first phase planning and direction, define the company's requirements in terms of what intelligence is required (Fleisher, 2001). According to Kahaner (1997), McGonagle and Vella (1999) and Rouach and Santi (2001) have highlighted the importance of this first phase in the Competitive intelligence process (Kahaner, 1997). This phase required knowledge about the intelligence user's key intelligence needs (KINs) including the timeframe.

Its is the decision-Makers who initiate the Competitive intelligence process by expressing what intelligence is required in order to make the most effective decisions. It is important to know that Competitive intelligence is not about collecting all information but focusing on issues of highest importance to senior management (Daft et al, 1988; Herring, 1998; Gilad, 1989). It is also about a wider focus than only on competitors to include facets such as suppliers, customers and the regulatory environment.

The key player involved in this process is decision makers and the CI team. The decision Makers represent any in the firm who require intelligence to improve the decision making process, most commonly included the Strategic Planners, Corporate Executives, General Managers, Functional Managers, Product Line Managers, Sales Force, etc. CI team is defined as the formal department created tm manager the Competitive intelligence process and meet the intelligence needs of the firm (Kahaner, 1996).

This requirement must be clear and non ambiguous. When the intelligence requirements are understood by the Competitive intelligence group, the next step involves transforming the intelligence requirements into information requirements. Perhaps some of this information already exists, perhaps not. The Competitive intelligence team must determine what additional information is required and process to acquire it.

The planning phase not only initiates the Competitive intelligence process, but also includes managing the end to end process as well as acting as the forum for feedback between the Competitive intelligence group and decision Makers. The feedback provides opportunities for revisions to the original intelligence request as well as constructive feedback on the deliverable of previous requests facilitating a continuous improvement atmosphere.

\subsection{Collection}

During this phase the information is collected from a variety of sources (primary and secondary) using various techniques (Viviers et al, 2005). Some common primary sources include government agencies, employees, suppliers, customers, conferences, etc. Some common secondary sources include magazines, TV, radio, analyst reports, and professional reports.

The choice of a particular source is related to the type of data or information required; such factors as ease of access ease of processing the source, cost, availability, quantity and quality of information will probably impact on selection (Wanderley 1999).

It is important to note the necessity for creativity and innovation in the acquisition of information. One of the greatest sources of information come from employees of the firm itself, therefore an effective communication infrastructure must exist to support the acquisition of the information.

Collection also involves various acquisition methods including environmental scanning (Aguilar, 1967; Lenz and Engledow, 1986; Daft et al., 1988), surveys, telephone interviews, observation, media scanning and networking.

\subsection{Analysis}

This phase is the most important step in any Competitive intelligence process. It includes the activities of analysis and synthesis of data collected. It is, converting information into usable intelligence on which strategic and tactical 
decisions may be taken (Gilad, 1989; Gilad and Gilad, 1985; Kahaner, 1996; Calof and Miller, 1997; Herring, 1998). It is here that meaning is attached to volumes of information and put in the context and decision-Makers require for effective decision making and it is the analysis that is responsible for adding value to the firm through enhancing the effectiveness of the decision making management.

Marceau and Sawka (1999) say that for intelligence to be relevant, advanced and appropriate analytical tools must be used such as SWOT (strengths, weaknesses, opportunities and threats) analysis, PEST (political/legal, economical, socio-cultural and technological) analysis, scenario analysis, and competitor profiling. According to Gilad and Gilad (1988), the analysis process comprises six steps: collating data, condensing information, drawing conclusions, building scenarios, studying implications for competitive positioning and suggesting recommendations for action.

\subsection{Communication}

The results of the Competitive intelligence process must be communicated to the customers of the Competitive intelligence process. Intelligence communication can take place via ad hoc reports, alerts, e-mails, presentations, news briefs, competitor files and special memos (Fleisher, 2001).

The communication also includes the evaluation of the Competitive intelligence process, the identification of its benefits and the assessment of its effectiveness in the decision making process (Santo, 2010). Feedback from the users is also important in the development and improvement of future Competitive intelligence plans, as well as the review and reassessment of the organizational strategy (Fleisher 2001).

\section{Competitive intelligence context}

Theoretically it is postulated that Competitive intelligence process consists of planning and focus, collection, analysis, and communication of intelligence. According to Calof and Dishman (2002), the Competitive intelligence process can be affected by certain contextual influences, namely organisational culture/awareness, the formal infrastructure and as employee involvement.

\subsection{Process and structure}

Competitive intelligence requires appropriate policies, procedures, and a formal (or informal) infrastructure so that employees may contribute effectively to the Competitive intelligence system. There is much support for a formal structure and a systematic approach to intelligence (Cox and Good, 1967; Cleland and King, 1975; Gilad and Gilad 1985, 1986; Ghoshal and Kim, 1986; Porter, 1980). Corporation support is defined here as the receptiveness of corporation to the presence of a formal Competitive intelligence process.

Competitive intelligence support impacts the whole Competitive intelligence effort. Corporation can be evaluate through the organizational structure, the organizational culture (knowledge sharing encouraged or discouraged within the corporation) and the level of financial support (budget as a \% of annual revenue). However, regardless of the debate all authors point that the success of Competitive intelligence process depends on gathering people and resources from a range of internal units and encouraging employees to contribute to, use and participate in the Competitive intelligence activities.

\subsection{Organisational awareness/culture}

To be used optimally, enterprise has needs to have an appropriate organizational awareness of Competitive intelligence and a culture of competitiveness (Garvin, 1993; Sinkula, 1994; Slater and Narver, 1995). There has been support for this awareness/culture construct in the area of market orientation (Gelb et al., 1991; Ghoshal and Kim, 1986; Ghoshal and Westney, 1991; Kohli and Jaworski, 1990; Narver and Slater, 1990; Pole et al., 2000; Slater and Narver, 1994, 1995, 2000).

It is also important to create the right environment for Competitive intelligence. Without proper awareness and attitudes that encourage both intelligence and information sharing, it is difficult to develop intelligence within an organisation.

Awareness and participation can be enhanced using various methods including having incentives available to recognise or reward useful - contributions (Fuld, 1995). The distinction between the Competitive intelligence process and contextual influences is represented in figure 1.

\section{Research methodology}

The concept of competitive intelligence is recent and is not sufficiently recognized in 
Tunisia companies (Wadie N., 2011). An exploratory qualitative study was considered appropriate in this case. According to Creswell (2004) exploratory research is well suited to situations in which the research problem is difficult to delimit and those in which the research problem is not well known.

Qualitative methods provide rich information for exploring a phenomenon that has not been studied before, allowing the researcher to gain a better understanding of the phenomena and to identify attitudes, and influences.

For this reason, the qualitative research aims to build an understanding of companies "lived" experience with competitive intelligence, and how they manage this activity. The three most common methods used in qualitative research are participant observation, in-depth interviews, and focus groups. Each method is particularly suited for obtaining a specific type of data.

Participant observation is appropriate for collecting data on naturally occurring behaviors in their usual contexts.

In-depth interviews are optimal for collecting data on individuals' personal histories, perspectives, and experiences, particularly when sensitive topics are being explored.

Focus groups are effective in eliciting data on the cultural norms of a group and in generating broad overviews of issues of concern to the cultural groups or subgroups represented.

For qualitative research two methods are used: In-depth interviews and focus group interviews. First, the use of In-depth interviews is gaining popularity among marketing researchers. In depth interviews provide detail about their personal experiences, views, and behaviour.

Focus groups are a very useful tool for collecting relevant and informative data. They allow researchers to investigate complex behaviour such as what different groups think about a subject and why they hold such views and can also help to identify changes in behaviour. Focus groups are particularly useful in investigating the use, effectiveness and usefulness of a service as they allow you to gather detailed information and probe people's views. They also enable the user to inform decision making and resource allocation.

In a complementary, focus group studies have used follow-up interviews with individual participants to explore specific opinions and experiences in more depth, as well as to produce narratives that address the continuity of personal experiences over time. Qualitative analysis for In-depth interviews and focus group discussion is a process of reviewing, synthesizing and interpreting data to describe and explain the phenomena or social worlds being studied. For this research one method is used: In-depth interviews.

\subsection{Sample profile}

The goal of an In-depth interview study is not necessarily broad application to the mass, but rather a unique understanding of an individual's groups' specific experience of a particular phenomenon. Since randomness is not an option in this qualitative inquiring, Patton (1990) recommended using relatively small selected purposefully. A purposeful sample selects information rich cases for study In-depth. For the In-depth interviews, a simple interview guide was self-constructed and was based on the elements of the Competitive intelligence processes. The guide of focus group was represented in the following. Three sectors were chosen for this study: communication technologies, manufacturing and commercial retailing. The research questions during the interviews were open and general. Notes, relating to salient aspects and in response to the prepared questions, were kept and typed up immediately after the interview. Information gathered was collated and analysed per key Competitive intelligence component of the Competitive intelligence process, and the research results were represented by descriptive statistics in the form of tables and figures. The interview guide:

\section{Planning and focus}

Management Issues and Decision: Definitions, evolution and relation to others fields (particularly strategy), Competitive intelligence process, CI roles

Early Warning Topics: Opportunities that company recognises first, threats including new emerging competitors and significant changes in industry, government, technology

Key players: Competitors, customers, others: Understanding of their capabilities and intentions, insight and foresight regarding action, and monitoring their activities on a ongoing basis.

\section{Collection}

From primary sources: methods and sources: employees, customers, suppliers, competitors, trade association officials, academics, reports, etc.

From secondary sources: World Wide Web, online and subscriber databases, newspaper, trade journals, and public records, etc. 


\section{Analysis}

PEST (political/legal, economical, socio-cultural and technological) analysis.

Scenario analysis.

Porter's five forces model, SWOT (strengths, weaknesses, opportunities and threats) analysis.

Competitor profiling.

\section{Communication}

Methods.

Process.

Channels.

Sender/receiver model.

\section{Process and structure}

Formal or informal infrastructure.

\section{Directing}

Evaluation and control

Managing the core CI work

Organizing.

Planning project management.

Staffing and structuring/location.

Organisational awareness and culture

Staff training

The In-interview began with sample biographical questions about the respondent such as their title, their tenure with the organization, their role and responsibilities at the firm. These questions were applied to gain rapport and to create a spirit of trust between the interviewer and participant.

The In-depth interviews conducted with six executives and took place during the period April-May 2010. The interviewers were contacted by telephone, briefing on the purpose and the nature of this study and assured confidentially of response. Next, they were requested to participate to conduct the interview. All interviews took place at the interviewees' work places. The interview ranged in duration from 40 to 60 minutes, with the average at approximately 50 minutes. The interviewer was tape-recorded and transcribed into text files for data analysis. Table 1 presents the sample of In-depth interviews.

The text analysis afforded opportunities to search for themes and patterns in responses, as recommended by Seidman (1991), who suggest marking individual passages, grouping them in categories and then studding the categories for thematic connection.

The text was reviewed and grouped by answers to the specific research questions (Hon, 1997), as well as contrasting and comparing multiple responses and remarks that set some interviews apart from the other. According to McCracken (1988) noted, by interviewing a number of respondents, the researcher was able to connect the experience of these participating and check the comments against other, offering validity to parallel remarks or contradictions to opposing remarks.

Following the recommendation of Berg (1988), themes were established from the body of the interviews and grouped based upon trends and patterns in answers specific to the research question.

\section{Findings}

\subsection{Planning and focus}

The initial suggestions about understanding competitive intelligence process shows that competitive intelligence is not very well recognised in Tunisia. Four respondents know that competitive intelligence is a process for gathering, analyzing, and managing external information about products, competitors, suppliers, regulators, partners, and customers. It is assumed by them to be a strategic activity. The respondent declared not to have any organised Competitive intelligence activities at all. In the majority of the cases the process for gathering, analyzing, and 
managing external information about products, competitors, suppliers, regulators, partners, and customers is practiced in the marketing and sales department.

The results of In-depth interview showed that some companies have employee's regularly contributing information without being informed about management's information needs. Further, for those few that informed the employees what to collect.

\subsection{Collection}

The questionnaire aimed to determine the information needs of respondents and where they looked for information sources (Table 2). Respondents were presented with nine types of information and they were asked to indicate on a three category scale (unimportant (1), important (2), very important (3)) to what extend they considered these types of information important. One of the more significant results of the study was all types of information as more important. Additionally, they had to indicate the two most important of information: profiles of potentials customers, opportunities in new market and reputation and activities of competitors.

Interviewers were presented with eight sources of information and they were asked to the three most important information sources (Table 3). The results chows that the important sources of information are quite similar in both companies: company staff, personal contacts outside the company and external distribution channels. Primary, personal and informal sources are frequently used, which suggests the importance of social networks for the intelligence process. The Internet was not also frequently referred to.

The majority of cases, companies spend most of their time in collecting information. Although planning what and how to collect information receives relatively less attention than suggested in intelligence literature (Calof and Breakspear, 1999; Perscott and Bhardwaj, 1995).

\subsection{Analysis}

Respondents were presented with seven different techniques which enable CI researchers and decision makers to place the collected data within a useful context for strategic decision making: Competitor profile, Market analysis, SWOT analysis, Porter's Five Forces, BCG Matrix, McKinsey Matrix, and Scenario analysis and asked if they recognised these techniques. The majority of respondents knows and uses the majority of these methods to analyze competitive information gathered especially useful in making decisions that fall the marketing department (Table 4).

\subsection{Communication}

In the six companies, we noted the concern of sharing information and circulate it. The majority of companies wanted to improve the organization, transmission and sharing of information internally. This is precisely the companies that were prepared to invest more in competitive intelligence and whose strategy was clearer and more explicit than others. The main forms of intelligence dissemination are face to-face meetings and reports.

\subsection{Process and structure}

The results of the Process/structure questions (how Competitive intelligence is organised and conduct in your company) indicate that companies may not yet be investing appropriately in building the internal infrastructure required for fully effective intelligence efficacy. Further, they reported that they conducted intelligence on a part-time basis with employees being responsible for their own intelligence. Although they indicated that they have not convenient ways for employees to report intelligence input.

\subsection{Culture, awareness and attitude}

Competitive intelligence is assumed to be a strategic activity by the majority of respondents. They said that employees understood that sharing information was important to the firm's success. This is indicative of a positive culture, awareness and attitude towards intelligence that might not, as evidenced earlier, be being fully supported by the process and structure.

\section{Conclusion}

In today's highly competitive business environment, it is essential for every business to understand what its competitors are doing and what they are planning to do. Competitive Intelligence has emerged as a separate business activity from market research and general business intelligence. It is a systematic a systematic process for planning and direction, data and information collection, analysis and dissemination of intelligence. The goal of Competitive intelligence is to provide actionable intelligence that will provide a competitive edge to the organization.

The purpose of this study was to explore the aspects of management of Competitive intelligence process in Tunisian companies. The results revealed by this study that the competitive intelligence as a competitive tool is unknown to 
the vast majority of Tunisian business. Only a very few companies employ it to be more competitive than their market competitors.

The results presented in this study indicate that the competitive intelligence in Tunisian companies is not still a formalized stage, but it is in an embryonic way. There are also situations where junior staff develop and distribute intelligence information to managers, including middle managers, who then provide intelligence for top management. Taken together with the results from the planning phase, this suggests that many companies have employees' regularly contributing information without being informed about management's information needs.

It is clear from the study that the two most important of information are collected: profiles of potentials customers, opportunities in new market and reputation and activities of competitors. A variety of information sources are utilized, including primary, personal and informal source, which suggests the importance of social networks for the intelligence process. The Internet was not also frequently referred to.

For analysing and synthesising information the results indicate that managers knows and uses the majority of these methods to analyze competitive information gathered especially useful in making decisions that fall the marketing department. The main forms of intelligence communication are face to face meetings and reports.

All companies spend most of their time in collecting information. Although planning what and how to collect information and analysis they receive relatively less attention.

The evidence from this research suggests that overriding influence on successful competitive intelligence process is the existence of a management support, culture and structure, which encourage trust, facilitate communication and encourage the easy flow of information.

The intelligence process and structure as well as the organizational awareness and culture are seen as having direct impact on all of the various phases in the intelligence competitive.

The elements of Competitive intelligence process consist of the following:

Identify the intelligence needs of the Decision-Makers (Planning);

Determine what information is required to generate the intelligence (Planning);

Acquire the necessary information (Collection);

Transform the information into the required intelligence (Analysis);

Dissemination the intelligence to the Decision-Makers (Dissemination);

Actively promote the utilisation of intelligence in the Decision-process (Utilization).

Each element in the process is important of the overall function.

Without a proper intelligence structure in companies, it is difficult to develop competitive intelligence. Competitive intelligence functions, like other corporate staffs, have a variety of needs that must be met. These needs fall into three broad categories: access to decision-making, visibility, links to other parts of the enterprise (Toit and Muller, 2004).

\subsection{Access to decision-making}

Three components in companies are responsible for the effective functioning of a Competitive intelligence unit, namely, top management, the staff of the Competitive intelligence unit and the line managers in their different functional areas. The intelligence activities of these groups must be coordinated. One proven way to bring Competitive intelligence into the decision-making process on an acceptable basis is to bring the decision makers into the Competitive intelligence process. Intelligence units must be located so that they are in a position to support decision making by providing competitive insights, discussing alternatives and compelling action. Whether intelligence units are addressing strategic or tactical must be as close to the decision maker as possible (Miller, 2000).

\subsection{Visibility}

According to McGonagle and Vella (1999), Competitive intelligence has become recognized as a vital, legal and ethical support for many corporate functions, such as planning and marketing. Intelligence units should be highly visible components of corporate organizations. Organizations clearly have a need to avoid creating the impression that they are not abiding by strict legal and ethical guidelines as they manage their intelligence programmes.

\subsection{Links to other parts of the enterprise}

Intelligence units should be located organizationally so that they have strong links to other parts of the enterprise. The majority of information that can be transformed into intelligence resides within most companies and if an intelligence unit is unable to access and acquire this internal information, it will not be able to conduct intelligence 
operations properly (Miller, 2000). Intelligence functions must be able to interact with other corporate components, for example sales and marketing, planning, purchasing and manufacturing.

Without the visible support of and utilization of intelligence by top management, the process will be flawed. Until recently, little thought was given on where in a corporate enterprise to place a Competitive intelligence unit. Strategic planning, or other functions akin to it, for the most part has been the most logical fallback location. Competitive intelligence units were concerned mainly with issues of strategic importance to a company, and the strategic planning department seemed to be the most logical choice for placing the intelligence function (Miller, 2000). The implementation of competitive intelligence unit in the organization seeks to help managerial process of the Competitive information. It also requires a cultural change in the collaborators that should have the freedom of putting their competitive information in a database without fear of safety lack. The key to tapping this internal resource in accomplishing the following four tasks (Festervand, 1988):

1. Sensitize personnel to the need for intelligence. An understanding of what competitive intelligence is what it potentially offers the agency and the acceptance of the individual's role in providing such is critical to employee cooperation and contribution.

2. Train employees to perform competitive intelligence. Without knowing how to conduct competitive intelligence (for example, listening to customers, reading relevant publications, observing competition, etc.) or what type of information is sought (for example, customers' ideas, complaints, competitive benefits, trends, etc.), it is doubtful that meaningful amounts of intelligence will be collected.

3. Provide an accessible channel through which intelligence can be transmitted (for example, weekly staff meetings).

4. Reward employees for their efforts. Effort for which no actual or perceived reward is attached will soon cease.

This study aims to investigate competitive intelligence process in Tunisia. It was qualitative in nature. The main limitation of the study relates to the small number of companies studied. In further research is needed to more understand the Competitive intelligence process in Tunisian companies as well to confirm the findings of this research.

\section{References}

Ashton W. B. and R. A. Kalvans. (1997). Keeping Abreast of Science and Technology. Columbus, Battelle.

Barson, D.C. (2002). Competing intelligently, Global Cosmetic Industry, Vol. 170 No. 6, pp. 26-8.

Berg, S. (1988). d'échantillonnage boule de neige, dans Kotz, S. et Johnson, NL (dir.) Encyclopédie des sciences de la statistique Vol. 8.

Berner S. (2001). Role and Function of Competitive Intelligence in Gaining Competitive Advantage (Online) Available: WWW: http://www.samberner.com/documents/KM/ci.pdf.

Bose, R. (2008), Competitive intelligence process and tools for intelligence analysis, Industrial Management \& Data Systems, Vol. $108 \quad \mathrm{~N}^{\circ}$. 4, pp. 510-28. doi:10.1108/02635570810868362, http://dx.doi.org/10.1108/02635570810868362

Bower, J.L., (1986). When Markets Quake, Harvard Business School Press, Boston, MA.

Calof, J.L. and Breakspear, A. (1999). Competitive Intelligence practices of Canadian technology firms, National Research Council/Canadian Institute of Scientific and Technical Information.

Calof, J.L. and Skinner, B. (1999). Government's role in competitive intelligence: What's happening in Canada? Competitive Intelligence Magazine, Vol. $2 \mathrm{~N}^{\circ}$ 2, pp. 20-30.

Creswell, J.W. (2004). Educational Research: Planning, Conducting, and Evaluating Quantitative and Qualitative Research, 2nd ed., Merrill Prentice-Hall, Columbus, OH.

Daft, R. L., Sormunen, J. and Parks, D. (1988). Chief executive scanning, environmental characteristics, and company performance: An empirical study, Strategic Management Journal. 9(2):123-139. doi:10.1002/smj.4250090204, http://dx.doi.org/10.1002/smj.4250090204

Dishman P. and Calof J. (2007). Competitive intelligence: a multiphasic precedent to marketing strategy, European Journal of Marketing, Vol. $42 \quad \mathrm{~N}^{\circ}$. 7/8, pp. 766-785. doi:10.1108/03090560810877141, http://dx.doi.org/10.1108/03090560810877141

Eisenhardt K.M. (1989). Building Theories from Case Study Research, The Academy of Management Review, Vol. $14, \mathrm{~N}^{\circ}$. 4. Oct., pp. 532-550.

Fair, W.R. (1966). The corporate CIA - a prediction of things to come, Management Science, Vol. $12 \mathrm{~N}^{\circ} 10$, pp. 489-503. doi:10.1287/mnsc.12.10.B489, http://dx.doi.org/10.1287/mnsc.12.10.B489 
Festervand T.A., Grove S.J. and Reidenbach R.E. (1988). The salesforce as a marketing investigation, Marketing Intelligence and Planning, Vol 18, ํ4, pp. 185-199.

Fleisher, C.S. (2001). An introduction to the management and practices of competitive intelligence (CI), in Fleisher, C.G. and Blenkhorn, D.L. (Eds), Managing Frontiers in Competitive Intelligence, Quorum Books, Westport, CT, pp. 3-18.

Fuld, L.M. (1995). The New Competitor Intelligence: The Complete Resource for Finding, Analyzing, and Using Information about Your Competitors, Wiley, New York, NY.

Gabbar, H. (2007). Intelligent topology analyzer for improved plant operation, Industrial Management \& Data Systems, Vol. 107, $\quad \mathrm{N}^{\circ} \quad 2, \quad$ pp. 229-250. doi:10.1108/02635570710723822, http://dx.doi.org/10.1108/02635570710723822

Garvin, D.A. (1993). Building a learning organization, Harvard Business Review, 71(4):78-91.

Gelb, B.D., Saxton, M.J., Zinkhan, G.M. and Albers, N.D. (1991). Competitive intelligence: insights from executives, Business Horizons, Vol. $34 \mathrm{~N}^{\circ}$ 1, pp. 43-7. doi:10.1016/0007-6813(91)90080-F, http://dx.doi.org/10.1016/0007-6813(91)90080-F

Ghoshal, S. and Kim, S.K. (1986). Building effective competitive intelligence systems for competitive advantage, Sloan Management Review, Vol. $28 \mathrm{~N}^{\circ}$ 1, pp. 49-58.

Ghoshal, S. and Westney, D.E. (1991). Organizing competitor analysis systems, Strategic Management Journal, Vol. $12 \mathrm{~N}^{\circ}$, pp. 1-15. doi:10.1002/smj.4250120103, http://dx.doi.org/10.1002/smj.4250120103

Gilad, B. (1989). The role of organized competitive intelligence in corporate strategy, Columbia Journal of World Business, 24(4), pp. 29-36.

Grabowski, D.P. (1987). Building an effective competitive intelligence system, Journal of Business \& Industrial Marketing, Vol. 2 №1, pp. 39-44. doi:10.1108/eb006016, http://dx.doi.org/10.1108/eb006016

Guyton, W.J. (1962). A guide to gathering marketing intelligence, Industrial Marketing, March, pp. 84-88.

Herring, J. (1998). What is intelligence analysis?, Competitive Intelligence Magazine, Vol. 1 No. 2, pp. 13-16.

Hon, L. C. (1997). What have you done for me lately? Exploring effectiveness in public relations, Journal of Public Relations Research, 9 (1), 1-30. doi:10.1207/s1532754xjprr0901_01, http://dx.doi.org/10.1207/s1532754xjprr0901_01

Huber G. P. (1986). The nature and the design of Post-Industrial organizations, Vol. 30, №. 5, pp. 928 - 951.

Kahana, M. J. (1996). Associate retrieval processes in free recall, Memory and Cognition, 24, 103-109. doi:10.3758/BF03197276, http://dx.doi.org/10.3758/BF03197276

Kahaner, L. (1996). Competitive Intelligence, Simon \& Schuster, New York, NY.

Kahaner, L. (1996). Competitive Intelligence: From Black Ops to Boardrooms - How Businesses Gather, Analyze, and Use Information to Succeed in the Global Marketplace, New York: Simon \& Schuster.

Kahaner, L. (1997). Competitive Intelligence, Touchstone, New York, NY.

Kahaner, L. (1998). Competitive Intelligence, Touchstone Books, New York, USA.

Kohli, A.K. and Jaworski, B.J. (1990). Market orientation: the construct, research propositions, and managerial implications, Journal of Marketing, Vol. 54, pp. 1-18. doi:10.2307/1251866, http://dx.doi.org/10.2307/1251866

Lenz, R., \& Engledow, J. (1986). Environmental analysis units ans strategic decision making: a field study of selected "leading edge" corporations. Strategic Management Journal, Vol. $7 . \quad$ pp. 69-89. doi:10.1002/smj.4250070107, http://dx.doi.org/10.1002/smj.4250070107

Marceau, S. and Sawka, K. (1999). Developing a World-Class CI Program in Telecoms, Competitive Intelligence Review. Vol. 10. $\quad \mathrm{N}^{\circ} \quad 4, \quad 30-40 . \quad$ doi:10.1002/(SICI)1520-6386(199934)10:4<30::AID-CIR6>3.0.CO;2-H, http://dx.doi.org/10.1002/(SICI)1520-6386(199934)10:4<30::AID-CIR6>3.0.CO;2-H

McCracken, G. (1988). The Long Interview, Newbury Park, CA: Sage.

McGonagle J.J. and Vella C.M. (1999). Environmental analysis units and strategic decision-making: a fuld study of selected leading-edge corporation, Strategic Management Journal, Vol 7, N4, pp. 69 - 89.

Miller, JP (2000), "Small business intelligence: People make it happen", in Miller, JP (Ed.) Millennium intelligence: Understanding and conducting competitive intelligence in the digital age. Medford, NJ, Information Today.

Narver, J.C. and Slater, S.F. (1990). The effect of a market orientation on business profitability, Journal of Marketing, Vol. $5 \mathrm{~N}^{\circ} 4$, pp. 20-35. doi:10.2307/1251757, http://dx.doi.org/10.2307/1251757

Patton M.Q. (1990). Qualitative Evaluation and Research Methods, Newburg Park: Sage. 
Pole, J.G., Madsen, E. and Dishman, P. (2000), Competitive intelligence as a construct for organizational change, Competitive Intelligence Review, Vol. $11 \quad \mathrm{~N}^{\circ} \quad 4, \quad$ pp. $25-31$. doi:10.1002/1520-6386(200034)11:4<25::AID-CIR5>3.0.CO;2-U, http://dx.doi.org/10.1002/1520-6386(200034)11:4<25::AID-CIR5>3.0.CO;2-U

Porter, M.E. (1980). Competitive Strategy: Techniques for Analyzing Industries and Competitors, The Free Press, New York, NY.

Prescott, J. E. and Bhardwaj, G. (1995). Competitive Intelligence Practices: A Survey. Competitive Intelligence Review, Vol. 6, № 2, pp.4-14. doi:10.1002/cir.3880060204, http://dx.doi.org/10.1002/cir.3880060204

Rouach, D. and Santi, P. (2001). Competitive Intelligence Adds Value: Five Intelligence Attitudes, European Management Journal, Vol. 19, $\quad \mathrm{N}^{\circ} \quad 5, \quad$ pp. 552-559. doi:10.1016/S0263-2373(01)00069-X, http://dx.doi.org/10.1016/S0263-2373(01)00069-X

Salles, M. (2006). Decision making and information requirements for competitive intelligence, Production Planning \& Control, Vol. 17, pp. 229-37. doi:10.1080/09537280500285367, http://dx.doi.org/10.1080/09537280500285367

Santos M. and, Correia A. (2010). Competitive Intelligence as a Source of Competitive Advantage: an Exploratory Study of the Portuguese Biotechnology Industry, 11th European Conference on Knowledge Management, 2-3 September, 2010, Famalicão, Portugal.

Seidman, I. E., (1991). Interviewing as Qualitative Research: A Guide for Researchers in Education and the Social Sciences, Teacher's College Press, New York, NY

Sinkula, J.M. (1994).Market information processing and organizational learning, Journal of Marketing, Vol. 58, pp. 35-45. doi:10.2307/1252249, http://dx.doi.org/10.2307/1252249

Slater, S.F. and Narver, J.C. (1995). Marketing orientation and the learning organization, Journal of Marketing, Vol. $59 \mathrm{~N}^{\circ}$ 3, pp. 63-74. doi:10.2307/1252120, http://dx.doi.org/10.2307/1252120

Society of Competitive Intelligence Professionals (SCIP) .(2008). Society of Competitive Intelligence Professionals, available at: www.scip.org/content.cfm?itemnumber=2226\&navItem Number=2227 (accessed 11 February).

Tidd J., Bessant J. and Pavitt K. (2001). Managing innovation - Integration Technological, Market and Organizational change, Second Edition Chichester: John Wiley and Sons.

Vedder, R.G. and Guynes, C.S. (2002). CIOs' perspectives on competitive intelligence, Information Systems Management, Fall 2002, pp49-55. doi:10.1201/1078/43202.19.4.20020901/38834.6, http://dx.doi.org/10.1201/1078/43202.19.4.20020901/38834.6

Viviers, W., Saayman, A. and Muller, M. (2005). Enhancing a competitive intelligence culture in South Africa, International Journal of Social Economics, Vol. 32 No. 7, pp. 576-89. doi:10.1108/03068290510601117, http://dx.doi.org/10.1108/03068290510601117

Wadie N. (2011). Competitive intelligence in Tunisian companies, Journal of Enterprise Information Management, Vol. 24 Iss: 1, pp.53-67

Wanderley, A. V. M. (1999). Um instrumento de macropolítica de informação: Concepção de um sistema de inteligência de negócios para gestão de investimentos de engenharia, Ciência da Informação, Vol. 28, pp. 190-199.

Zangoueinezhad A. ana Moshabaki A. (2008).The role of structural capital on competitive intelligence, Industrial Management \& Data Systems, Vol. 109 №2, pp. 262-280. doi:10.1108/02635570910930136, http://dx.doi.org/10.1108/02635570910930136

Table 1. Sample of In-depth interviews

\begin{tabular}{|c|c|c|}
\hline Companies/direction & Sector & Responsibility of respondent \\
\hline 1. & Communication and technologies & Customer service manager \\
\hline 2. & Communication and technologies & Marketing director \\
\hline 3. & Manufacturing & Commercial director \\
\hline 4. & Manufacturing & Commercial director \\
\hline 5. & Retailing & Finance director \\
\hline 6. & Retailing & Marketing director \\
\hline
\end{tabular}


Table 2. Importance of type of information

\begin{tabular}{lcrrrrr}
\hline \multicolumn{1}{c}{ Types of information } & \multicolumn{2}{c}{$\begin{array}{c}\text { Telecommunication and } \\
\text { technologies }\end{array}$} & \multicolumn{2}{c}{ Manufacturing } & \multicolumn{2}{c}{ Retaling } \\
& Rank & Rank & Rank & Rank & Rank & Rank \\
\hline Profiles of potentials customers & 3 & 3 & 3 & 3 & 3 & 3 \\
Opportunities in new market & 3 & 3 & 3 & 3 & 3 & 3 \\
Reputation and activities of competitors & 3 & 3 & 3 & 3 & 3 & 3 \\
Distribution channels & 2 & 2 & 3 & 3 & 3 & 3 \\
Culture & 2 & 2 & 2 & 2 & 2 & 2 \\
Technological development & 3 & 3 & 2 & 2 & 2 & 2 \\
Political environment & 2 & 2 & 2 & 2 & 2 & 2 \\
Statistical information about markets & 3 & 3 & 3 & 3 & 2 & 2 \\
Regulation, barriers & 2 & 2 & 3 & 3 & 3 & 3 \\
\hline
\end{tabular}

Table 3. Importance of sources of information

\begin{tabular}{lcccccc}
\hline \multicolumn{1}{c}{ Sources of information } & \multicolumn{2}{c}{$\begin{array}{c}\text { Telecommunication and } \\
\text { technologies }\end{array}$} & \multicolumn{2}{c}{ Manufacturing } & & \multicolumn{2}{c}{ Retaling } \\
& Rank & Rank & Rank & Rank & Rank & Rank \\
\hline Information of company staff & 1 & 1 & 1 & 1 & 1 & 1 \\
External distribution channel & 2 & 3 & 3 & 2 & 2 & 2 \\
Personal de contacts outside company & 3 & 2 & 2 & 3 & 3 & 3 \\
Internet & 4 & 5 & 8 & 8 & 4 & 4 \\
Published information & 6 & 6 & 4 & 6 & 6 & 6 \\
Government publications markets & 7 & 7 & 5 & 5 & 8 & 7 \\
Regulation, barriers & 8 & 8 & 7 & 7 & 7 & 8 \\
Internal document & 5 & 4 & 6 & 4 & 5 & 5 \\
\hline
\end{tabular}

Table4. Knowledge of Methods of competitive intelligence analysis

\begin{tabular}{lcc}
\hline Methods of competitive intelligence analysis & Frequency & Percentage \\
\hline Competitor profile & 4 & 67.0 \\
Market analysis & 4 & 67.0 \\
SWOT analysis & 4 & 67.0 \\
Porter's Five Forces & 6 & 100 \\
BCG Matrix & 4 & 67.0 \\
McKinsey Matrix & 3 & 50.0 \\
Scenario analysis & 2 & 34.0 \\
\hline
\end{tabular}

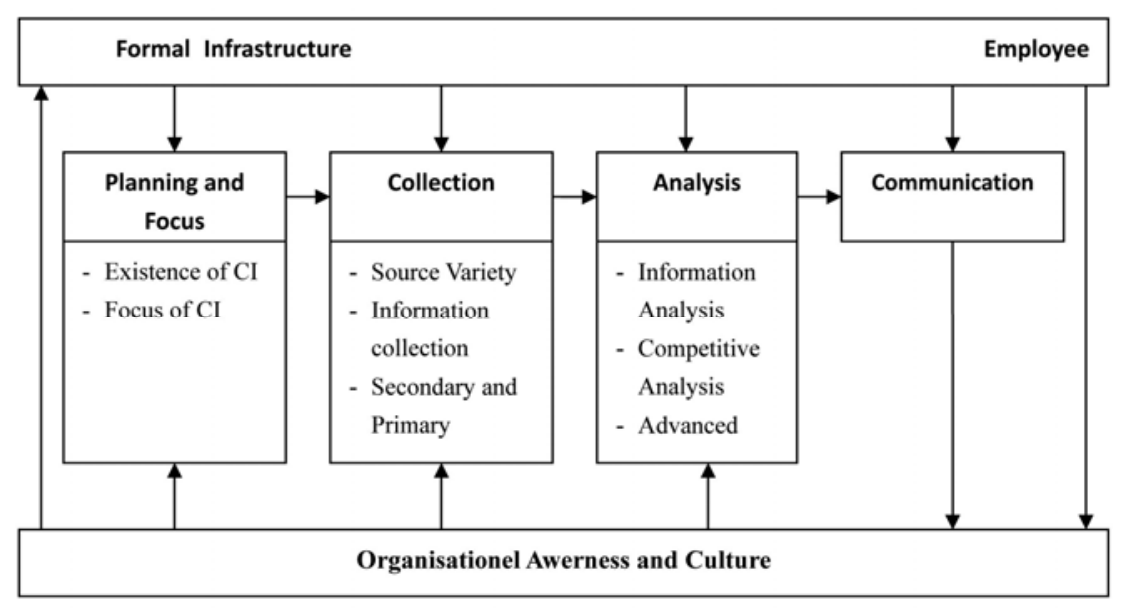

Figure 1. Calof and Dishman's model of competitive intelligence

Source: Adopted Calof and Dishman (2002) 